\title{
Fetal Doppler Monitoring
}

National Cancer Institute

\section{Source}

National Cancer Institute. Fetal Doppler Monitoring. NCI Thesaurus. Code C114081.

A technique that utilizes a Doppler transducer to monitor fetal heart rate. The transducer

is placed on the maternal abdomen and detects fetal cardiac motion using ultrasound. 